HANDBOOK OF THE

BIRDPPIJE WORLD ORNITHOLOGICAL NOTES

Notes on the vocalizations of Blackish-blue Seedeater (Amaurospiza moesta) and allies

Peter Boesman

In the following we briefly analyze and compare voice of Blackish-blue Seedeater (Amaurospiza moesta), Blue Seedeater (A. concolor) and Carrizal Blue Seedeater ( $A$. carrizalensis). We also try to quantify the extent of any vocal differences using the criteria proposed by Tobias et al. (2010), as a support for taxonomic review.

We have made use of sound recordings available on-line from Keno Canto (XC).

A comparison of song, illustrated with sonograms:

A. moesta
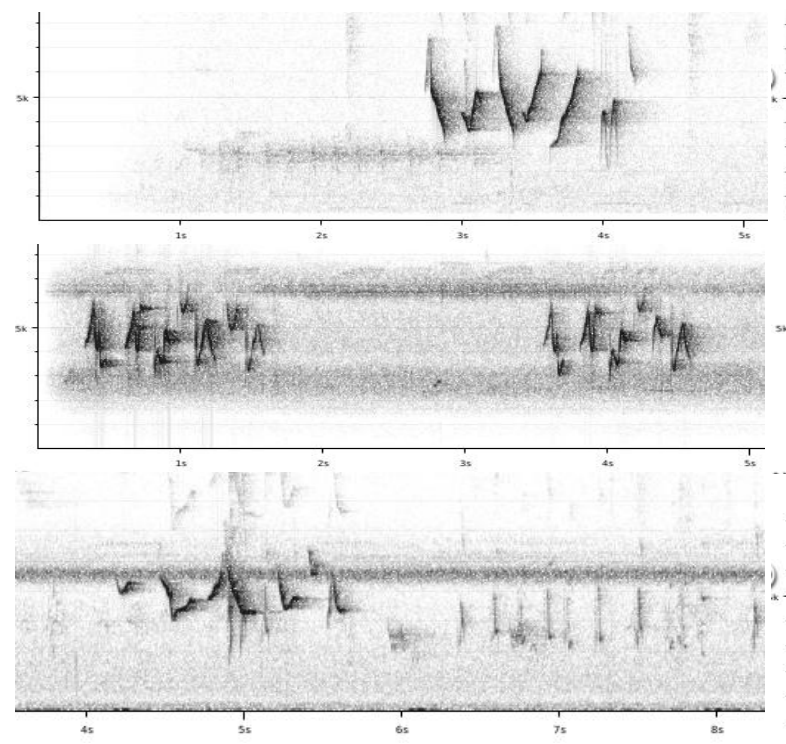
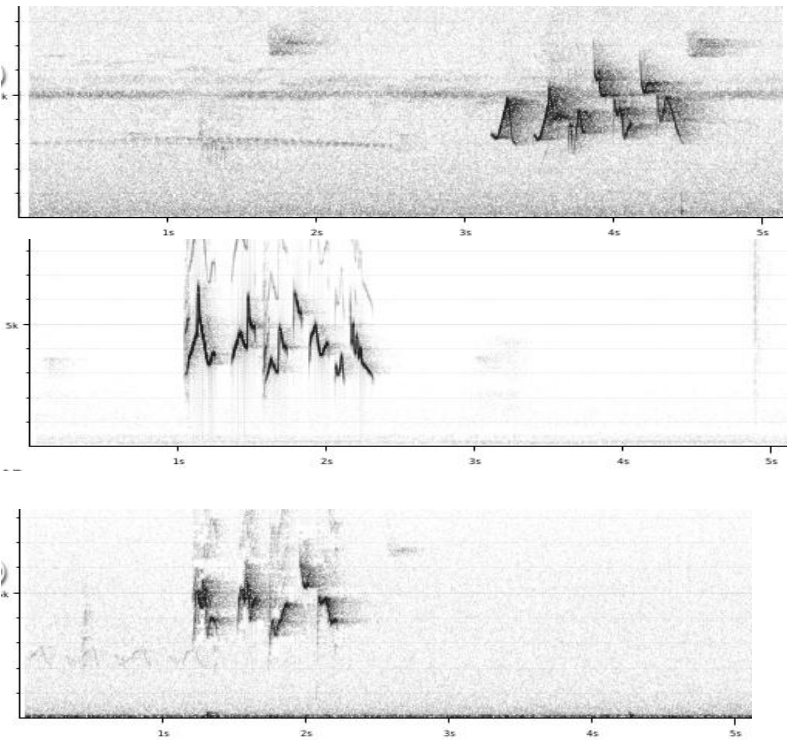

A. concolor

Ecuador (aequatorialis)
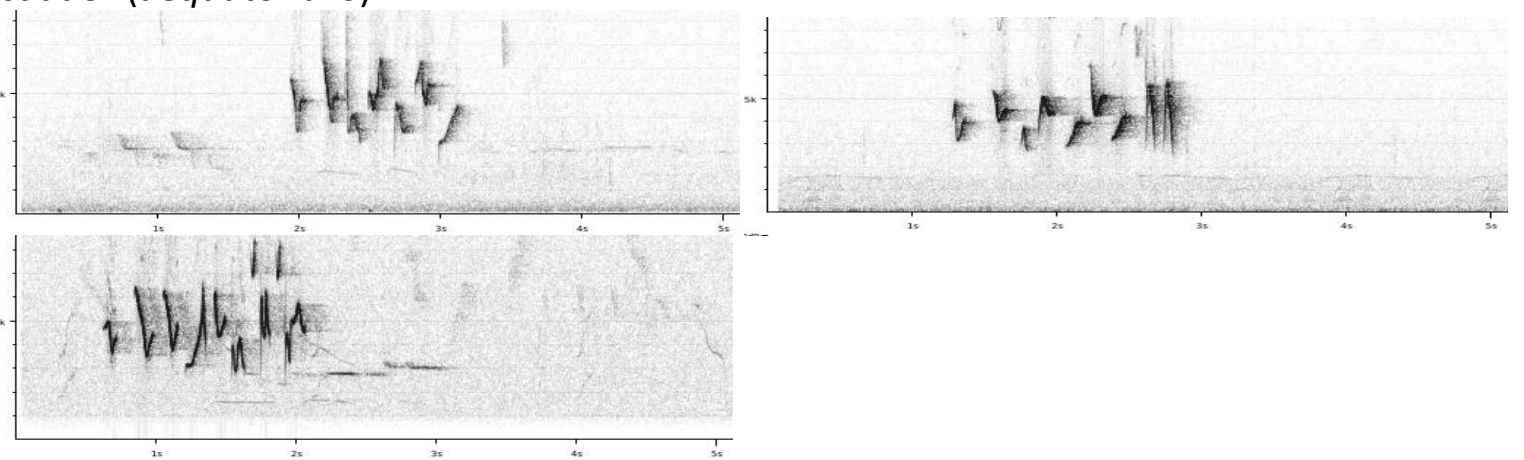

1 

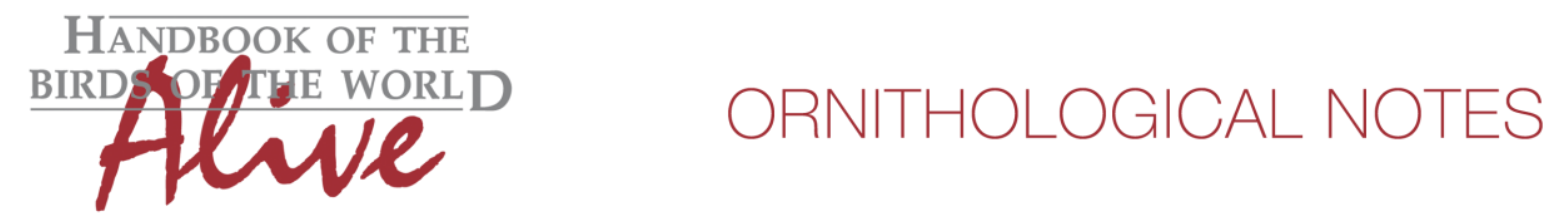

Chiapas, Mexico (nominate)

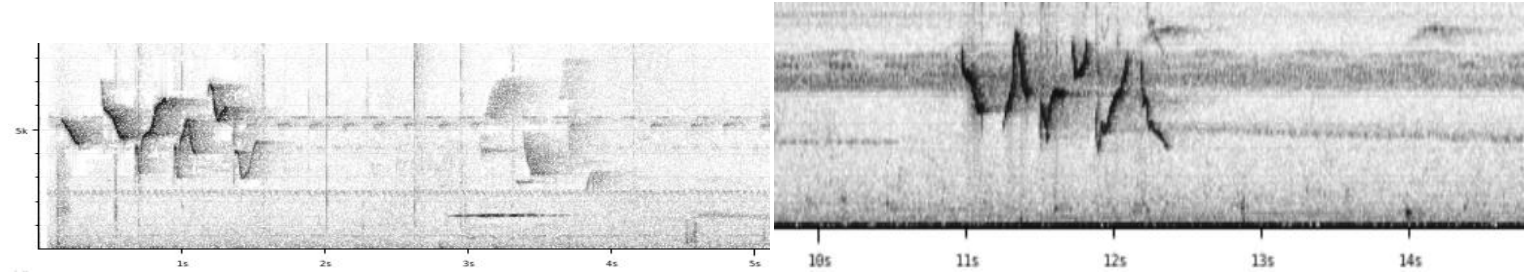

(We have not found any recordings of song of race relicta).

\section{A. carrizalensis}

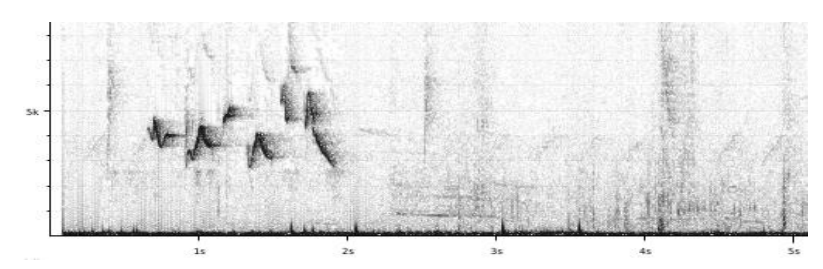

From the above examples, it is clear that song of all three species is very similar, given the range of variation within each species.

All basic sound parameters have a largely overlapping range (min. frequency, max. frequency, number of notes, note length, phrase length,...). Note shapes are also quite similar, with many about identical between species.

Other features that may allow differentiation such as e.g. at start or end of a song phrase could not be found.

It is probably impossible to assign any recording with a reasonable level of confidence to any species. A multivariate statistical analysis may allow to separate song of the different taxa (once more recordings become available), but in any case differences will be small, and will not lead to scores higher than e.g. $1+1$ applying Tobias criteria.

This note was finalized on 28th July 2016, using sound recordings available on-line at that moment. We would like to thank the many sound recordists who placed their recordings for this species on XC, in particular Jonathan Miranda for the recordings of carrizalensis.

\section{References}

Tobias, J.A., Seddon, N., Spottiswoode, C.N., Pilgrim, J.D., Fishpool, L.D.C. \& Collar, N.J. (2010). Quantitative criteria for species delimitation. Ibis 152(4): 724-746. 


\section{Recommended citation}

Boesman, P. (2016). Notes on the vocalizations of Blackish-blue Seedeater (Amaurospiza moesta). HBW Alive Ornithological Note 388. In: Handbook of the Birds of the World Alive. Lynx Edicions, Barcelona. (retrieved from http://www.hbw.com/node/1252945 on 1 December 2016). 